\title{
Characteristics of Road Traffic Accident Cases Reported in a Tertiary Military Hospital
}

\author{
Rahman MM1 1 , Zafreen F2 2 , Uddin ANMM ${ }^{3}$
}

DOI: https:/ / doi.org/ 10.3329/ jafmc.v15i2.50842

\begin{abstract}
Introduction: Road traffic accidents (RTA) are the eighth leading cause of death globally, and the leading cause of death in Bangladesh. The road safety situation in Bangladesh has been deteriorating with increasing number of road accident deaths, largely as direct consequences of rapid growth in population, motorization, urbanization and lack of investment in road safety.

Objectives: To describe the injury characteristics of road traffic accidents cases that reported at Combined Military Hospital (CMH), Dhaka.

Materials and Methods: This descriptive cross-sectional hospital based study was conducted on all the RTA cases reported to medical inspection room $\mathrm{CMH}$, Dhaka from 01 March to 30 June 2010. A total of 126 RTA victims irrespective of age and sex were included, data were collected by face to face interview using a pretested questionnaire.
\end{abstract}

Results: A total of 126 road traffic accident victims both sexes were studied. The majority of the study subjects were men 103 (81.7\%) and most of them were in 31-40 years group (27\%), Muslims $(98.41 \%)$ were the majority. In our study regarding educational qualification of RTA victims most of them were SSC qualified (44'4\%) and primary level (15.1\%). Military services holder (45.2\%) was the majority of road traffic crash victims. Bus/Minibus (32.5\%) was responsible for the majority of road traffic crashes and motor vehicle passengers $(42.9 \%)$ were main victims. Laceration \& cut injury were (38.1\%) and multiple injury (18.3\%) were the most common injury. Main roads (49.2\%) were the commonest site of the accidents. Regarding place of occurrence main roads 62 (49.2\%) was the most common site and noon 41 (32.5\%) was the most common time of occurrence of accidents.

Conclusion: Road traffic crashes constitute a major public health problem in our setting and contribute significantly to unacceptably high morbidity and mortality. Urgent preventive measures targeting at reducing the occurrence of road traffic crashes is necessary to reduce the morbidity and mortality resulting from these injuries. Early recognition and prompt treatment of road traffic injuries is essential for optimal patient outcome.

Key-words: Road traffic accidents, Victims, Injury characteristics, Military hospital.

\section{Introduction}

Accident is an incident, occurring suddenly, unpredictably and unintentionally under unforeseen conditions. Road traffic accidents (RTA) can be defined as an accident that occurs on a way or street open to public traffic, resulting in one or more persons being killed or injured, and involving at least one moving vehicle. Accordingly, RTAs are collisions between vehicles, between vehicles and pedestrians, between vehicles and animals, or between vehicles and geographical or architectural obstacles ${ }^{1}$. RTA is a serious public health problem and a major cause of disability worldwide 2 . According to the World Health Organization (WHO) report in 2010, 2 road traffic injuries (RTI) have been identified as the ninth most common cause of disability adjusted life years (DALYs) lost for all age and gender categories. WHO reported that 1.24 million people were killed on the road, and up to 50 million people were injured worldwide, and the number of road traffic deaths is expected to increase 3,4 further by 2020. Nearly three-quarters of overall road deaths occur in developing countries, although road deaths are common in developed countries ${ }^{3}$. Bangladesh has a very high road accident fatality rate with official figures indicating more than 60 deaths per 10,000 motor vehicles. Everyday around eight persons die in road accidents. The actual rate of fatality is likely to be even higher. The problems related to the accident reporting system and the data derived from it, have not been resolved and official statistics are prone to under reporting. The number of accidents has increased by $43 \%$ between 1982 and 2000, while the number of fatalities has increased by around $400 \%$ within the same period ${ }^{4}$. This indicates that not only the occurrence of accidents is on the rise; the severity of accidents is also increasing. As the population, total road length and modal share of road transport continue to grow in the country, the number of casualties from road accidents is expected to maintain its rising trend. Most motorized vehicles in Bangladesh are concentrated in Dhaka City. Consequently, almost a fifth of road accidents in Bangladesh take place in Dhaka ${ }^{4}$. In Bangladesh as a whole, buses and trucks are each involved in more than $20 \%$ of accidents ${ }^{4}$. According to the prediction, rapid urbanization and motorization in low and middle income countries will account for much of the traffic crash deaths increase, and this number is expected to increase significantly in the next two decades if without appropriate injury prevention measures to control the problem. In many countries, rising rates of RTIs and consequent increases in deaths accompanied rapid economic growth and intensive motorization. One of the main factors contributing to more road traffic crash deaths is the growing number of motor vehicles in lowand middle-income countries. According to a report, many of the deaths due to road traffic crashes occurred in the emerging motorized countries ${ }^{5}$. The objectives of this paper were to report characteristics of people killed in road traffic crashes and to describe major patterns of traffic crashes.

\section{Materials and Methods}

A descriptive type of cross sectional study was carried out at MI Room, CMH Dhaka, Dhaka cantonment from 01 March' 2010 to 30

1. Lt Col Md Moshiur Rahman, MBBS, MPH, Trainee Officer on MPhil Course, AFMI, Dhaka (E-mail: dr.sipon@gmail.com) 2. Dr Farzana Zafreen, MBBS, MPH, Associate Professor \& Head, Department of Community Medicine, Medical College for Women \& Hospital, Uttara, Dhaka 3. Col Abu Noman Mohammed Mosleh Uddin, MBBS, MPH, MPhil, Associate Professor of Community Medicine, AFMC, Dhaka. 
June' 2010. Study population was all the road traffic accident cases reporting at MI Room of CMH Dhaka irrespective of age and sex. Inclusion Criteria for Study Subjects was all the reported cases enlisted in the 'special event statement register' of MI Room CMH Dhaka as Road Traffic Accident patient from 01 March' 2010 to 30 June' 2010 irrespective of age and sex. Both military and civil were selected as study population. During this time period there were 126 Road Accident victims enlisted and I have selected all 126 cases purposively so sample size was 126 . Sampling Technique was Nonprobability purposive type of sampling technique. Data Collection Tool(s)/Instrument(s) were a structured questioner. Data were collected by scrutinizing the hospital records (special event statement register) of road traffic accident cases and the relevant data were recorded in the checklist. After collection of data, raw data from checklist were scrutinized for any error, checked to see whether it was filled completely and consistently. Data analysis was made keeping in mind the objectives of the study by SPSS 11.0. Data were expressed in frequencies, percentage, different tables, bar diagram, pie charts as applicable. In case of ethical consideration, the study required to collect some personal information from the medical records. So before collection of data, a written application was made to the hospital authority about the purpose of the study. Permission was obtained and undertaking given that such data will have used only for research purpose.

\section{Results}

Total 126 victims socio-demographic characteristics are shown in table-I. About involvement of different types of vehicles; the study revealed that most of the accidents were committed with bus/minibus 41 (32.5\%) followed by jeep/car/taxi 33 (26.2\%) and motorcycle $17(13.5 \%)$. In respect of types of victims this study revealed that pedestrians were 40 (31.7\%), motor vehicle passengers $54(42.9 \%)$, motor vehicle drivers including motor cycles $23(18.3 \%)$. The morbidity pattern of victims revealed laceration \& cut injury were $48(38.1 \%)$; remaining cases were abrasion $20(15.9 \%)$, fracture $20(15.9 \%)$, multiple injury 23 (18.3\%), head injury 06 (4.8\%) (Table-II). Regarding place of occurrence, the commonest site was main roads 62 (49.2\%); remaining were highways $37(29.4 \%)$, lanes 24 (19.0\%) and level crossing $03(2.4 \%)$ (Figure-1). Figure-2 shows the distribution of RTA occurrence within four hour bracket both in frequencies and percentage (\%) out of total 126 study cases. It was observed that during daytime official working periods were vulnerable for committing accidents. Distribution of the injury pattern according to place of occurrence, the study revealed that among the 126 cases maximum number of injury was laceration and cut injury 48 (38.1\%) and that was more common in main roads accident, then followed by multiple injury $23(18.2 \%)$ and that was more common in highways accidents, abrasion and fracture $20(15.9 \%)$ are more common in main roads accident, head injury 06 (4.8\%) are more common in highways accidents (Table-III). According to the types of vehicles involved and time of occurrence the study revealed that out of 126 cases maximum accidents 41(32.5\%) occurred by bus \& minibus then followed by jeep/car/taxi 33 (26.2\%), Motorcycle 17(13.5\%), Autorickshal Tempo 16(12.7\%), Microbus/ Pickup 12(9.5\%), Train and Trucks/ Covered van 03(2.4\%) and Rickshaw/ Rickshaw Van 01(0.8\%). In case of time of occurrence maximum accidents occurred at noon 41 (32.5\%), then followed by afternoon $34(27.0 \%)$, evening 25 (19.9\%), morning 18 (14.3\%), mid night 07 (5.5\%) and Late night $01(0.8 \%)$ (Table-IV).
Table-l: Socio-demographic characteristics of the respondents (n-126)

\begin{tabular}{|l|l|c|c|}
\hline \multicolumn{2}{|c|}{ Characteristics } & Frequency & Percentage \\
\hline \multirow{4}{*}{ Age in years } & $\leq 10$ & 7 & 5.6 \\
\cline { 2 - 4 } & $11-20$ & 9 & 7.1 \\
\cline { 2 - 4 } & $21-30$ & 33 & 26.2 \\
\cline { 2 - 4 } & $31-40$ & 34 & 27.0 \\
\cline { 2 - 4 } & $41-50$ & 23 & 18.3 \\
\cline { 2 - 4 } & $51-60$ & 19 & 15.1 \\
\cline { 2 - 4 } & $\geq 61$ & 1 & 0.8 \\
\hline \multirow{4}{*}{ Gender } & Male & 23 & 18.3 \\
\cline { 2 - 4 } & Female & 103 & 81.7 \\
\hline \multirow{4}{*}{ sdigion } & Muslam & 124 & 98.41 \\
\cline { 2 - 4 } & Hindu & 2 & 1.59 \\
\hline \multirow{4}{*}{ Occution } & Illiterate & 12 & 9.5 \\
\cline { 2 - 4 } & Primary & 19 & 15.1 \\
\cline { 2 - 4 } & Secondary & 12 & 9.5 \\
\cline { 2 - 4 } & SSC & 56 & 44.4 \\
\cline { 2 - 4 } & HSC & 13 & 10.3 \\
\cline { 2 - 4 } & Graduate & 14 & 11.1 \\
\hline & Military & 57 & 45.2 \\
\cline { 2 - 4 } & Civil & 18 & 14.3 \\
\cline { 2 - 4 } & Students & 13 & 10.3 \\
\cline { 2 - 4 } & Drivers & 3 & 2.4 \\
\cline { 2 - 4 } & Others & 35 & 27.8 \\
\hline
\end{tabular}

Table-II: Distribution of RTA victims by type of vehicle involved, type of victims and morbidity pattern ( $n=126)$.

\begin{tabular}{|c|c|c|c|}
\hline \multicolumn{2}{|r|}{ Attributes } & Frequency & Percentage \\
\hline \multirow{8}{*}{$\begin{array}{l}\text { Type of } \\
\text { vehicle }\end{array}$} & Bus/Minibus & 41 & 32.5 \\
\hline & Jeep/Car/Taxi & 33 & 26.2 \\
\hline & Motor cycle & 17 & 13.5 \\
\hline & $\begin{array}{l}\text { Auto } \\
\text { Rickshaw/Tempo }\end{array}$ & 16 & 12.7 \\
\hline & Microbus/Pickup & 12 & 9.5 \\
\hline & Truck/Covered Van & 03 & 2.4 \\
\hline & Train & 03 & 2.4 \\
\hline & $\begin{array}{l}\text { Rickshaw/Rickshaw } \\
\text { van }\end{array}$ & 01 & 0.8 \\
\hline \multirow{5}{*}{$\begin{array}{l}\text { Types of } \\
\text { victims }\end{array}$} & Pedestrian & 40 & 31.7 \\
\hline & $\begin{array}{l}\text { Motor vehicle } \\
\text { passenger }\end{array}$ & 54 & 42.9 \\
\hline & Motor vehicle driver & 23 & 18.3 \\
\hline & $\begin{array}{l}\text { Non-motor vehicle } \\
\text { passenger }\end{array}$ & 07 & 5.6 \\
\hline & Rickshaw puller & 02 & 1.6 \\
\hline \multirow{6}{*}{$\begin{array}{l}\text { Morbidity } \\
\text { pattern }\end{array}$} & Abrasion & 20 & 15.9 \\
\hline & Laceration, Cut injury & 48 & 38.1 \\
\hline & Fracture & 20 & 15.9 \\
\hline & Multiple injury & 23 & 18.3 \\
\hline & Head injury & 06 & 4.8 \\
\hline & Others & 09 & 7.1 \\
\hline
\end{tabular}




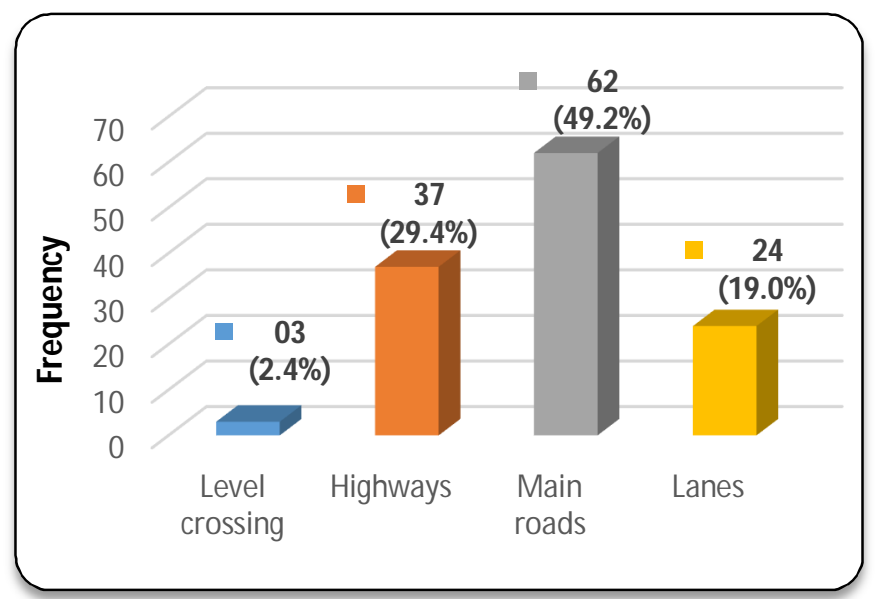

Figure-1: Distribution of RTA victims according to their place of occurrence $(\mathrm{N}=126)$

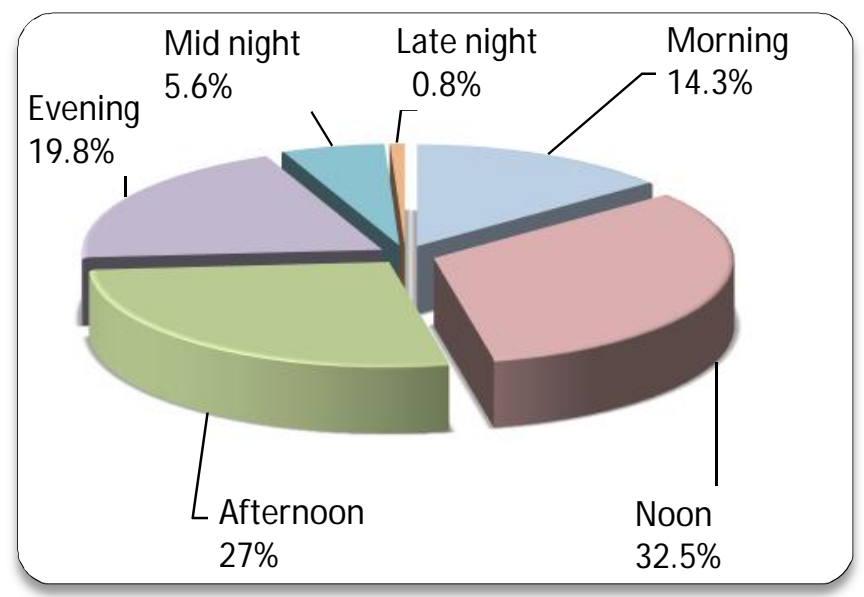

Figure-2: Time distribution of occurrence of RTA cases, $(\mathrm{N}=126)$

Table-III: Distribution of the injury pattern according to place of occurrence $(n=126)$.

\begin{tabular}{|l|c|c|c|c|c|}
\hline \multirow{2}{*}{\multicolumn{1}{c|}{ Injury Pattern }} & \multicolumn{3}{|c|}{ Place of occurrence } & \multirow{2}{*}{ Total } \\
\cline { 2 - 5 } & Level crossing & Highways & Main roads & Lanes & $20(15.9)$ \\
\hline Abrasion & 00 & $02(1.6)$ & $12(9.5)$ & $06(4.8)$ & $48(38.1)$ \\
\hline Laceration, cut injury & 00 & $12(9.5)$ & $28(22.2)$ & $08(6.3)$ & $20(15.9)$ \\
\hline Fracture & 00 & $06(4.8)$ & $08(6.3)$ & $06(4.8)$ & $23(18.2)$ \\
\hline Multiple injury & $02(1.6)$ & $13(10.3)$ & $07(5.5)$ & $01(0.8)$ & $06(4.8)$ \\
\hline Head injury & $01(0.8)$ & $03(2.4$ & $02(1.6)$ & 00 & $09(7.1)$ \\
\hline Others & 00 & $01(0.8)$ & $05(4.0)$ & $3(2.4)$ & $126(100)$ \\
\hline Total & $03(2.4)$ & $37(29.4)$ & $62(49.2)$ & $24(19.0)$ & \\
\hline
\end{tabular}

Table-IV: Distribution of types of vehicles and time of occurrence of RTA cases $(n=126)$

\begin{tabular}{|c|c|c|c|c|c|c|c|}
\hline \multirow[b]{2}{*}{ Type of vehicle } & \multicolumn{6}{|c|}{ Time of occurrence } & \multirow[b]{2}{*}{ Total } \\
\hline & $\begin{array}{l}\text { Morning } \\
6-10 \mathrm{am}\end{array}$ & $\begin{array}{c}\text { Noon } \\
10 \text { am-2 pm }\end{array}$ & $\begin{array}{c}\text { Afternoon } \\
2-6 \mathrm{pm}\end{array}$ & $\begin{array}{l}\text { Evening } \\
6-10 \mathrm{pm}\end{array}$ & $\begin{array}{l}\text { Mid night } \\
10 \mathrm{pm}-2 \mathrm{am}\end{array}$ & $\begin{array}{c}\text { Late night } \\
2-6 \mathrm{am}\end{array}$ & \\
\hline Train & 00 & 00 & $01(0.8)$ & $02(1.6)$ & 00 & 00 & $03(2.4)$ \\
\hline Trucks/Covered van & 00 & 00 & $01(0.8)$ & $02(1.6)$ & 00 & 00 & $03(2.4)$ \\
\hline Bus/Minibus & $08(6.3)$ & $14(11.1)$ & 09(7.1) & $07(5.5)$ & $02(1.6)$ & $01(0.8)$ & $41(32.5)$ \\
\hline Jeep/Car/Taxi & $06(4.8)$ & 15 (11.9) & $06(4.8)$ & $06(4.8)$ & 00 & 00 & $33(26.2)$ \\
\hline Microbus/Pickup & 00 & $06(4.8)$ & $01(0.8)$ & $02(1.6)$ & $03(2.4)$ & 00 & $12(9.5)$ \\
\hline Autoricksha/Tempo & $02(1.6)$ & $02(1.6)$ & $09(7.1)$ & $02(1.6)$ & $01(0.8)$ & 00 & 16(12.7) \\
\hline Motorcycle & $02(1.6)$ & $04(3.2)$ & $07(5.5)$ & $03(2.4)$ & $01(0.8)$ & 00 & 17(13.5) \\
\hline Rickshaw/Van & 00 & 00 & 00 & $01(0.8)$ & 00 & 00 & $01(0.8)$ \\
\hline Total & 18(14.3) & $41(32.5)$ & $34(27.0)$ & $25(19.9)$ & $07(5.5)$ & $01(0.8)$ & $126(100)$ \\
\hline
\end{tabular}

\section{Discussion}

Socio-demographic characteristics of the study subjects 126 trauma patients who visited MI Room, CMH Dhaka cantonment from 01 March'2010 to 30 June 2010. According to age group most of them were in 31-40 years group (27\%) then followed by, 21-30 years group (26.2\%), $41-50$ years group (18.3\%), 51-60 years group (15.1\%), $11-20$ years group (7.1\%), up to 10 years group(5.6\%) and 61 and above age group (0.8\%) respectively which was similar with Lili Xiong et al6. The study participants comprised of 126 (81.7 \%) men and 65 (18.3 \%) women, this finding was consistent with previous studies by others $6,7,11,16$. In concern to Religion of the respondents most of them were Muslims (98.41\%). In our study regarding educational qualification of RTA victims most of them were SSC qualified (44'4\%) then followed by primary level (15.1\%), Graduation \& above (11.1\%), HSC level (10.3\%) and illiterate and high school level (9.5\%). A study by Seid et al. showed that educational status of road traffic accident victims, $165(71.74 \%)$ of them had attended formal school of which $59(35.76 \%)$ and 73 $(44.24 \%)$ of the victims had a primary and secondary school education respectively while $33(20.00 \%)$ of the victims had reported higher educational level education?. According to their occupation of 126 RTA victims, military services were the maximum in number (45.2\%) then followed by civil and civil employees $(14.3 \%)$, students $(10.3 \%)$, drivers \& helpers $(2.4 \%)$ and other include businessmen, housewives, day labours, street beggars and address less were altogether $27.8 \%$. This finding is consistent with previous studies by others $7,8,9,10$. According to the involvement of different types of vehicles, most of the accidents were committed with the involvement of Bus/Minibus (32.5\%), and then followed by Jeep/Car/Taxi (26.2\%), Motorcycle (13.5\%), Auto rickshaw/Tempo 
(12.7\%), Microbus/Pickup (9.5\%), Train and Truck/Covered van (2.4\%) then Rickshaw/Rickshaw Van (0.8\%), Similar observation was reported by other study ${ }^{11}$. In respect of types of victims this study revealed that most of the respondents were motor vehicle passengers $(42.9 \%)$ then followed by pedestrians (31.7\%), motor vehicle drivers (18.3\%), non-motor vehicle passengers (5.6\%) and rickshaw puller/bicycles (1.6\%) respectively. In agreement with other studies ${ }^{11-14}$, pedestrians $(55.4 \%)$ accounted for the majority of road traffic victims and but in contrast with other studies which reported passengers as the majority of cases $^{7,10}$. Regarding the Injury characteristics of the respondent most common injury was found accounting laceration \& cut injury were (38.1\%), then followed by multiple injury (18.3\%), abrasion and fracture (15.9\%), other forms of injuries (7.1\%) and head injury (4.8\%) that agree with other study by Museru LM ${ }^{16}$. A study from France reported open wounds as the most frequent injury categories, followed by fractures, dislocations, and sprains ${ }^{16}$. The Nigerian study reported soft tissue injuries (71.9\%) and fractures as the most common type of injuries and head and neck as the most common injury site ${ }^{17}$. More than a third of their patients had multiple injuries, and tibia and fibula were the most common bone fractured ${ }^{17}$. The Indian study reported head, neck, and face as the most frequent injury site (32.44\%), followed by the upper extremities (21.01\%) and the lower extremities (19.68\%) ${ }^{18}$. They also found abrasions as the commonest injury type (56.38\%), with contusions (22.34\%) and lacerations (21.27\%) occurring almost equally ${ }^{18}$. Regarding the conditions of the victims during the occurrence of the accidents, the commonest site was main roads (49.2\%) then followed by highways (29.4\%), lanes (19.0\%) and level crossing (2.4\%). Regarding the time of RTA occurrence it was observed that during daytime and official working periods were vulnerable for committing accidents that is agreement with other studies 7,11 .

Distribution of the injury pattern according to place of occurrence, the study revealed that among the 126 cases maximum number of injury was laceration \& cut injury $48(38.1 \%)$ and that was more common in main roads accident, then followed by multiple injury 23 (18.2\%) and that was more common in highways accidents, abrasion and fracture $20(15.9 \%)$ are more common in main roads accident, head injury 06 (4.8\%) are more common in highways accidents. According to the types of vehicles involved and time of occurrence the study revealed that out of 126 cases maximum accidents $41(32.5 \%)$ occurred by bus \& minibus then followed by jeep/car/taxi 33 (26.2\%), Motorcycle 17(13.5\%), Autorickshal Tempo 16(12.7\%), Microbus/ Pickup 12(9.5\%), Train and Trucks/ Covered van 03(2.4\%) and Rickshaw/ Rickshaw Van $01(0.8 \%)$. In case of time of occurrence maximum accidents occurred at noon 41 (32.5\%), then followed by afternoon 34 (27.0\%), evening $25(19.9 \%)$, morning $18(14.3 \%)$, mid night 07 (5.5\%) and late night $01(0.8 \%)$.

\section{Conclusion}

This study showed males were 4.5 times more prone to accidents than female, thus creating enormous economic hardship due to loss of breadwinners. Road traffic accidents are predictable and preventable but good data are important to understand the ways in which road safety interventions can be effective. Accident data from present study and also from different sources suggests that there is a lack of proper enforcement and education to roadway safety. These weaknesses can be minimized through comprehensive corrective measures. Local community initiatives to improve the conditions are very sparse and it is also concluded that much greater effort, desirably with the support from international agencies and specialized institutes is needed in combating the problem. Importantly, such efforts would require considerable resources particularly trained local personnel, safety specialists and researchers so as to build up indigenous capacity and attain sustainable safety program. It is also important that road safety audits should be systematically implemented for preventing road accidents in Bangladesh.

\section{Recommendations}

Following recommendations are made on the basis of findings and relevant discussion on the study:

1) A standard accident reporting format may be introduced for facilitating appropriate treatment measure and smooth conduct of accident research in future.

2) Professional training and education regarding traffic rules among the military drivers may prevent/reduce the accidents of military vehicles.

3) Periodic awareness programs should be conducted regarding the use of footpath, foot over bridge and zebra crossing mainly by garment workers.

4) Appropriate management of civil RTA victims may be ensured by speeding up of under construction 500 bedded Kurmitola General Hospital.

5) All the Level crossing alongside Banani-Airport road should be well maintained and kept under appropriate supervision round the clock.

6) Compulsory wearing of safety belts by the vehicle drivers /car passengers and use of crush helmet/safety helmet by the motorcycle drivers as well as back seaters should be ensured and monitored by legal authority.

7) Strengthen the provision of prehospital and hospital trauma care alongside the vulnerable roads and implementation of appropriate legislation.

8) Improvement of the road condition, imposition of the speed limit/ speed breakers, marking of the danger points with sufficient road signs, repair of the unfit bridges etc are recommended.

\section{References}

1. Hailemichael F, Suleiman M and Pauolos W. Magnitude and outcomes of road traffic accidents at Hospitals in Wolaita Zone, SNNPR, Ethiopia. BMC Research Notes 2015; 8:135.

2. Lee JS, Kim YH, Yun JS, Jung SE, Chae CS, Chung MJ. Characteristics of Patients Injured in Road Traffic Accidents According to the New Injury Severity Score. Ann Rehabil Med 2016; 40(2):288-93.

3. Mansuri FA, Al-Zalabani AH, Zalat MM et al. Road safety and road traffic accidents in Saudi Arabia. Saudi Med J 2015; 36(4):418-424.

4. Maniruzzaman KM and Mitra R. Road Accidents in Bangladesh. IATSS Research 2005; 29(2):71-3.

5. Zhang X, Yao H, Hu G et al. Basic Characteristics of Road Traffic Deaths in China. Iranian Journal of Public Health 2013; 42(1):7-15. 
6. Xiong $L$ and $L i ~ L$. Single-vehicle and Multi-Vehicle Accidents Involving Motorcycles in a Small City in China: Characteristics and Injury Patterns. AIMS Public Health 2015; 2(1):74-85.

7. Seid M, Azazh A, Enquselassie $F$ et al. Injury characteristics and outcome of road traffic accident among victims at Adult Emergency Department of Tikur Anbessa specialized hospital, Addis Ababa, Ethiopia: A prospective hospital based study. BMC Emergency Medicine 2015; 15:10.

8. Chalya PL, Mabula JB, Dass RM et al. Injury characteristics and outcome of road traffic crash victims at Bugando Medical Centre in Northwestern Tanzania. J Trauma Manag Outcomes 2012; 6(1):1.

9. Akinpelu OV, Oladele AO, Amusa YB et al. Review of road traffic accident admissions in a Nigerian Tertiary Hospital. East Cent Afr J Surg. 2007; 12(1):64-7.

10. Chalya PL, Mabula JB, Ngayomela IH et al. Motorcycle injuries as an emerging public health problem in Mwanza City, north-western Tanzania. Tanzan J Health Res 2010; 12:214-21.

11. Chalya PL, Mabula JB, Dass RM et al. Injury characteristics and outcome of road traffic crash victims at Bugando Medical Centre in Northwestern Tanzania. Journal of Trauma Management \& Outcomes 2012; 6:1.
12. Akinpelu OV, Oladele AO, Amusa YB et al. Review of road traffic accident admissions in a Nigerian Tertiary Hospital. East Cent Afr J Surg 2007; 12(1):64-7.

13. Jha N, Agrawal CS: Epidemiological study of road traffic accident cases. A study from Eastern Nepal. Region Health Forum WHO South-East Asia Region 2004; 8(1):15-22.

14. Odero W, Garner P, Zwi A. Road traffic injuries in developing countries: a comprehensive review of epidemiological studies. Trop Med Int Health 1997; 2:445-60.

15. Museru LM, Leshabari MT. Road traffic accidents in Tanzania: A 10-year epidemiological appraisal. East Cent Afr J Surg 2002; 7:23-6.

16. Lapostolle A, Gadegbeku B, Ndiaye A et al. (2009) The burden of road traffic accidents in a French Department: the description of the injuries and recent changes. BMC Public Health 2009; 9:386.

17. Madubueze CC, Chukwu COO, Omoke NI et al. Road traffic injuries as seen in a Nigerian teaching hospital. Int Orthop 2011; 35(5):743-6.

18. Farooqui JM, Chavan KD, Bangal RS S et al Pattern of injury in fatal road traffic accidents in a rural area of western Maharashtra, India. Australian Medical Journal 2013; 6(9):476-82 . 